\title{
Entrevista
}

\section{ENTREVISTA COM GABRIEL GRABOWSKI: DECISÃO DA ELITE BRASILEIRA É ESTANCAR O ACESSO À EDUCAÇÃO BÁSICA E SUPERIOR}

Para o professor e pesquisador Gabriel Grabowski, as políticas educacionais dos governos de Michel Temer e de Jair Bolsonaro têm como objetivo claro transformar professor e estudante em protagonistas secundários no processo da educação.

Por Cristiano Goldschmidt ${ }^{1}$

Nesta entrevista, o professor e pesquisador Gabriel Grabowski fala do sucateamento da educação brasileira. Segundo ele, o movimento político de ataques às universidades e de cortes nos investimentos começou ainda em 2014, intensificando-se nos governos de Michel Temer e Jair Bolsonaro. A conversa aconteceu a partir do lançamento do livro A desconstrução do futuro (Carta Editora, 2019), obra composta de vinte e cinco artigos escritos mensalmente, de janeiro de 2017 a janeiro de 2019, nos quais o autor narra os retrocessos impostos à educação ao longo de dois anos. Assim como nesta entrevista, em seu livro Grabowski propõe uma reflexão sobre o impacto das reformas e a ausência de um projeto de educação no conjunto das políticas públicas para o setor, bem como alerta sobre a falta de perspectivas que essas políticas e programas impõem, de forma irresponsável, aos jovens - desconstruindo o futuro do país. Segundo o professor, são medidas que comprometem não só o futuro dos jovens que atualmente estão nas universidades, mas principalmente o das novas gerações, que já sentem o impacto negativo de um conjunto de propostas que colocam professor e estudante como protagonistas secundários no processo da educação. Como bem assinala o professor Gaudêncio Frigotto na apresentação da obra, o autor convida a um embate teórico e éticopolítico ao analisar "as medidas e contrarreformas que interditam a dupla cidadania para a maioria dos jovens da classe trabalhadora e condenam o Brasil ao trabalho simples e a ser uma nação sem autonomia e soberania".

Gabriel Grabowski possui Graduação em Filosofia Plena pela Faculdade de Filosofia Ciências e Letras Dom Bosco (1985), Especialização em Sociologia (UFRGS, 1997), Mestrado em Educação Profissional (UFRGS, 2004), Doutorado em Educação (UFRGS, 2010) e MBA de Gestão Universitária pela UCS/Comung (2017). Atualmente é docente e pesquisador da Universidade Feevale, em Novo Hamburgo (RS); pesquisador do Programa de Qualidade Ambiental e Mestrado em Letras; e professor do Centro Universitário Metodista de Educação (IPA), em Porto Alegre (RS). Integra a Diretoria da Associação de Escolas Superiores de Formação de Profissionais do Ensino (Aesufope) e o Conselho Estadual de Educação do Rio Grande do Sul (CEEd/RS). Mantém uma coluna mensal no Jornal Extra Classe (www.extraclasse.org.br), editado pelo Sindicato dos Professores do Ensino Privado do RS. Seus estudos e pesquisas versam sobre os seguintes temas: Educação e Trabalho, Financiamento da Educação e Financiamento da Educação

\footnotetext{
${ }^{1}$ Cristiano Goldschmidt é Jornalista, Escritor e Crítico Teatral. Pedagogo, possui Especialização em Pedagogia da Arte (Ufrgs, 2013), Especialização em Docência no Ensino Superior (Centro Universitário Leonardo da Vinci, 2018) e Mestrado em Artes Cênicas (Ufrgs, 2018). Atualmente é Conselheiro Estadual de Cultura do Governo do Estado do Rio Grande do Sul.
} 
Profissional, Ensino Médio, Educação Profissional, Juventude e Formação de Professores.

Confira a entrevista.

\section{1 - Como o senhor recebeu a notícia divulgada recentemente de que o governo cortará $30 \%$ do orçamento destinado às Universidades Federais?}

Grabowski: Esse anúncio nos causa uma profunda apreensão sobre o futuro da educação no país. Hoje (02/05/2019) os jornais estão estampando que de 2014 a 2018 nós já tivemos uma redução de investimentos na educação na ordem de 56\%. E para você ter uma ideia, o orçamento do MEC de 2014 a 2018 já teve uma queda de 117 bilhões para 103 bilhões. E a rubrica específica de investimentos que seria para ampliar a qualidade e o acesso à educação básica e superior no Brasil teve um decréscimo de 11,3 bilhões para 4,9 bilhões, e a projeção para esse ano de 2019 na peça orçamentária é de uma queda maior ainda, ou seja, o investimento baixaria para 4,2 bilhões. Isso demonstra uma tendência que começou em 2014, que é a redução real de investimentos na educação no Brasil. Quando você soma essa redução dos investimentos nesta ordem de mais de 50\% com a PEC 95 do teto dos gastos, aprovada em 2016, e este anúncio de agora, de uma redução de mais de 30\%, significa que sim, a nossa educação está ameaçada, em todos os sentidos: ameaçada quanto a sua oferta, ameaçada a sua qualidade, e obviamente não teremos nenhuma expansão no ensino superior nem na educação profissional, e o próprio ensino médio torna-se ameaçado. Mesmo que o ministro diga que vai priorizar a Educação Básica, esta redução está ocorrendo em todos os níveis e modalidades. Nós já temos um ensino médio que não está universalizado. Hoje, em torno de $80 \%$ dos jovens que deveriam estar no ensino médio estão matriculados, porém, apenas $50 \%$ concluem o ensino médio. Então nós teremos um retrocesso extremamente grave na educação brasileira, maior do que já está ocorrendo. E isso compõe, no meu entendimento, esta decisão da elite brasileira de estancar o acesso à educação básica e superior. Ou seja, 2014 teríamos atingido o teto de acesso à educação, e a partir daí começa um retrocesso, porque, de fato, não só estamos retrocedendo nestes investimentos, mas também em termos de acesso e de matrículas no ensino superior, por exemplo. Os últimos dois censos do INEP já demonstram que a educação brasileira está com menos alunos do que estava há quatro anos. A educação básica e o ensino médio também, ou seja, todos os níveis e modalidades demostram uma diminuição no número de alunos num momento em que nós temos um "bônus demográfico", no momento em que nós temos mais jovens no Brasil. Consequentemente esses jovens não terão acesso à educação pública em nosso país.

\section{2 - Abordada em um dos textos do seu livro, a BNCC (Base Nacional Comum Curricular) para a formação de professores é questionada pelos docentes. Quais são as questões levantadas?}

Grabowski: Acho que a primeira crítica mais séria em relação à BNCC é de que a própria proposta da BNCC para a formação de professores veio posteriormente à BNCC da Educação Básica. Primeiro tivemos a aprovação da BNCC do ensino infantil e 
fundamental em 2017, tivemos a aprovação da BNCC do ensino médio em 2018, e hoje o que tem é apenas uma proposta de BNCC que foi enviada pelo MEC ao Conselho Nacional de Educação, e agora o MEC a solicitou de volta para fazer ajustes com a perspectiva e a concepção do novo governo. Ou seja, estamos até este momento apenas com uma proposta, e uma proposta ainda não publicizada o suficiente. Toda reforma curricular deveria ter o caminho inverso. Primeiro você teria que pensar a preparação dos professores, a formação dos professores para uma nova concepção de educação básica como a BNCC tenta propor, e nesse caso o processo está invertido, ou seja, os últimos a terem uma BNCC serão os professores. Essa BNCC da formação dos professores, além de estar em ordem invertida, na verdade ela propõe que o professor seja um mero operador da aprendizagem e de um currículo pré-formatado. Essa decisão de propor e implementar a BNCC da formação dos professores significa que as editoras no Brasil vão preparar o material, o conteúdo, o desenvolvimento de competências e habilidades dos alunos e irão oferecer isso aos sistemas de ensino através de material didático, apostilas e livros didáticos, e o professor será apenas o executor disso lá na escola, dentro da lógica da BNCC. Isso vai mais uma vez contribuir para a desconstituição da docência, a desvalorização da docência. E esses ataques hoje que se faz às escolas, às universidades e aos docentes ditos marxistas, na verdade é um movimento amplo de tornar o professor um mero instrumento de implementação do currículo que as grandes editoras, os grandes grupos empresariais de educação vão preparar para que ele opere e implemente dentro da escola. Então a crítica é de instrumentalização da função docente. Tanto o professor quanto o estudante serão protagonistas secundários no processo da educação. A educação que está sendo planejada e implementada no Brasil desde 2014 é uma educação profundamente controlada pelo Estado, que por sua vez é controlada pelos grandes grupos empresariais na perspectiva do capital. Com isso, a escola, o estudante e o professor receberão um pacote educacional, um processo de aprendizagem já planificado para desenvolverem no tempo e no espaço escolar.

\section{3 - De que forma a nova BNCC da educação básica prejudicará os jovens mais pobres?}

Grabowski: Inicialmente precisamos diferenciar as BNCCs, porque nós temos duas BNCCs, e essa é uma outra crítica. Hoje a nossa LDB (Lei de Diretrizes e Bases) prevê que a educação básica, que envolve educação infantil, ensino fundamental e médio, é um todo, uma unidade, que deveria ser pensada, planejada e desenvolvida de forma bem integrada. Esse é um dos avanços importantes que a LDB de 1996 propiciou à educação brasileira, a partir, inclusive, de uma concepção do próprio autor, o senador e educador Darcy Ribeiro, de que a educação básica é um todo que precisa estar integrado, articulado e desenvolvido. O que a BNCC fez então? ela dividiu e rompeu esta unidade da educação básica. Nós temos uma BNCC do ensino infantil e fundamental, e outra do ensino médio. Sobre a primeira, ela traz essa grande mudança de que a partir dela não mais trabalharemos conteúdos, saberes e conhecimentos - através de disciplinas -, mas desenvolveremos competências e habilidades. Nós não temos ainda uma experiência e um acúmulo acadêmico e cultural de como desenvolver competências e habilidades em 
crianças de educação infantil, por exemplo, ou do ensino fundamental. Essa é uma novidade para a qual nós não temos expertise e não temos a formação dos professores. Então será um desafio que pode inclusive causar uma desorganização do que nós temos hoje de estrutura curricular na educação infantil e fundamental. E esse é um desafio muito grande. Pelo que nós conhecemos a nível internacional, nenhum país fez uma mudança curricular desta ordem e tão radical, substituindo currículos organizados e estruturados de forma disciplinar e interdisciplinar, passando para esse currículo de competências e habilidades na educação infantil. Por quê? Porque esse currículo de competências tem uma origem e uma natureza dentro da educação chamada técnica-profissional. Onde ela foi implementada num primeiro momento, como França, Canadá, foi na formação profissional de nível médio, que são os cursos técnicos, e que o sistema "S" (SENAI, SENAC, SESI, SEBRAE) no Brasil já faz há muito tempo, ou no ensino superior, porque por sua função precípua o ensino superior profissionaliza, e é onde nós temos uma experiência maior e expertise melhor. Agora, fazer isso na educação infantil é algo que acende todos os alertas possíveis. E o que essa BNCC propôs? O desenvolvimento de dez competências que são as mesmas para a educação infantil, ensino fundamental e ensino médio. Então nós temos dez competências a serem desenvolvidas para toda a educação básica. O que muda é a complexidade e o aprofundamento que cada etapa deverá fazer no desenvolvimento das próprias competências. $O$ que a BNCC altera fundamentalmente? Ela torna obrigatório apenas as disciplinas de português e matemática no ensino fundamental e no ensino médio, além do inglês, mas não garante que os demais componentes curriculares sejam mantidos com espaço dentro do currículo, como, por exemplo, o estudo de ciências da natureza e do meio ambiente no ensino fundamental, e o estudo das ciências humanas no ensino médio. Ela não garante isso, e esse é um desafio. O segundo, é que tem outra mudança na BNCC do ensino médio. Ele colocou um teto máximo de formação no ensino médio quanto à formação geral. A Base Nacional Comum para todo o Brasil deverá ter no máximo 1800 horas, das 3000 horas do ensino médio. As outras 1200 horas a escola deverá optar por um dos cinco itinerários, que é aprofundar a formação em ciências humanas, ou matemática, ou ciências da natureza, ou linguagens, e o quinto itinerário é o ensino técnico profissional. Isso significa um possível risco para jovens, que consiste em ele ter um ensino médio com apenas 1800 horas de formação geral, de cultura geral para todas as áreas, e isso é uma redução do nosso atual currículo. Obviamente isso afetará a qualidade, e as próprias escolas particulares estão muito preocupadas, porque pela primeira vez na legislação se fixou um máximo de carga horária no ensino médio - 1800 horas -, quando sempre a legislação fixava uma carga horária mínima, como: de 800 horas até 1200 h para os cursos técnicos. Agora não, eles colocaram o máximo, que é 1800h para cultura geral - restringindo currículos - e, mais outras 1200 horas de um dos 5 itinerários. Então, primeiro haverá uma diminuição da formação geral, segundo deverá haver uma escolha por um itinerário a ser aprofundado em detrimento dos outros, e se possibilita que depois o jovem fique estacionado no ensino médio fazendo itinerários alternadamente. Ou seja, será uma educação de qualidade inferior ao que nós temos hoje, ocupará o jovem mais tempo fazendo itinerários no ensino médio e inibindo a sua continuidade nos estudos no ensino superior. Portanto, eu avalio que o impacto 
sobre a vida do jovem será, provavelmente, um ensino médio de qualidade inferior, que não o preparará para a continuidade dos estudos a nível superior e visa mantê-lo com apenas a formação básica, sem incentivá-lo a progredir nos estudos de graduação e de pós-graduação.

\section{4 - Que análise o senhor faz das Diretrizes Curriculares para o Novo Ensino Médio (DCNEM), que propõem que $40 \%$ do currículo poderá ser na modalidade EaD e institui até o trabalho voluntário na carga horária dos alunos?}

Grabowski: A chamada Reforma do Ensino Médio, que também começa em 2016 com o governo Temer, tem três instrumentos. Um instrumento é esse da BNCC sobre a qual falamos agora. Antes dela, em outubro de 2016, o presidente Michel Temer alterou a LDB através de Medida Provisória. Essa é outra novidade, pois pela primeira vez na história da LDB ela foi alterada por meio de uma MP, de cima para baixo, arbitrariamente. Ela, que é uma lei aprovada pelo Congresso Nacional, a nossa constituição da educação, sendo alterada por uma forma impositiva. Então, o Temer encaminha uma alteração dessa LDB em 2016, e que virou a Lei 13.415 em fevereiro de 2017. Ou seja, nós temos uma lei nova do ensino médio que justamente abriu e anunciou um "novo" ensino médio. O que tem de "novo aqui"? É o que eu acabei de falar: um ensino médio em cinco itinerários, com a não obrigatoriedade mais das disciplinas que o compunham, restringindo-o apenas a matemática e português, podendo ser ofertado por módulos, por competências e habilidades, e de formas diversificadas. Teremos vários ensino médio pelo país. Então, essa lei abre estas possibilidades de configurações diversas de formação básica. A aprovação das novas diretrizes para o ensino médio foi muito rápida, pois o Conselho Nacional de Educação começou a discutir a atualização em outubro e, em dezembro de 2018, já estavam aprovadas as Novas Diretrizes para o Ensino Médio e a BNCC também. O que esses três instrumentos buscam consolidar? Um "novo" ensino médio que se propõe em tempo integral - e não educação integral -, tempo integral quer dizer o aluno ficar mais tempo na escola, no mínimo sete horas, e que esse currículo do ensino médio terá, no máximo, 1.800 horas de cultura geral mais um dos cinco itinerários (de 1.200h), totalizando 3.000 horas. Este ensino médio poderá ser ofertado através de Educação a Distância, sendo $20 \%$ no diurno e $30 \%$ no noturno. Isto significa que, se a escola optar pelo quinto itinerário de formação técnica, esse itinerário poderá ser feito todo em $\mathrm{EaD}$. Cabe lembrar que nós temos no Brasil uma oferta de ensino noturno muito grande, que somado à condição juvenil, em função da sua carência social e econômica, trabalha e estuda com muitas dificuldades, poderá cursar o itinerário na modalidade de EaD. E nós já temos na educação profissional uma grande oferta de cursos técnicos em EaD, seja na rede particular, seja principalmente no sistema "S" (SENAC, SESI, SENAI, SEBRAE). Esta rede privada poderá se apresentar como parceiros ofertantes de cursos do itinerário técnico profissional para o ensino médio da rede pública, através da EaD. E, também, prevê que o jovem incorpore toda e qualquer experiência, de trabalho e voluntariado, como carga horária desse itinerário. Quer dizer que, se um jovem fizer estágio, um jovem que participa de um projeto de voluntariado, poderá compor o currículo com estas atividades. Cursos de qualificação profissional, com certificações parciais, poderão 
compor a carga horaria do $5^{\circ}$ itinerário também. Se todas estas atividades poderão servir como carga horária para o ensino médio, isto significa que o jovem ficará menos tempo na escola que hoje, precarizando sua formação ainda mais.

\section{5 - O senhor aborda em outro texto do seu livro a questão do juvenicídio, falando dos altos índices de jovens assassinados no Brasil. Gostaria que o senhor falasse um pouco sobre isso.}

Grabowski: O juvenicídio é uma categoria que foi desenvolvida por um pesquisador mexicano - Prof. José Manuel Valenzuela -, que estuda a violência praticada contra os jovens na América Latina, desde o México - onde temos grandes episódios de matança de jovens -, mas ele traz isso para Argentina e outros países, como Guatemala, Equador e Brasil. $\mathrm{O}$ artigo reflete a relação entre falta de educação para nossa juventude e o alto índice de mortes desta juventude. Do total de homicídios no Brasil, bem como do total de presos no Brasil, a grande maioria são jovens que deveriam estar no ensino médio ou na universidade. Da nossa população carcerária atual, em torno de 800 mil presos, $70 \%$ a $80 \%$ são jovens. E dos 63/64 mil homicídios ano no Brasil, em torno de 54\% são de jovens, ou seja, mais de 50\% dos homicídios são de jovens de 15 a 17 anos que deveriam estar no ensino médio. Por não estarem no ensino médio e por falta de oportunidades profissionais, visto que o desemprego atinge mais os jovens, eles se tornam presas muito mais fáceis do crime organizado, inclusive dentro do sistema prisional. Eles estão disponíveis para as facções os capturarem em seus respectivos territórios da periferia na maioria das grandes cidades. Tanto que o homicídio no Brasil é de Norte a Sul. Ele não tem uma região ou um Estado em que ele prepondere, quer dizer, se mata hoje no Norte e no Nordeste tantos jovens como no Rio de Janeiro, em São Paulo e aqui em Porto Alegre. Inclusive, entre as 50 cidades mais violentas do mundo divulgadas pela ONU, 17 são brasileiras, e entre as 17, Porto Alegre é uma delas. Todos imaginam que seja o Rio de Janeiro, que não está entre essas 17. Trago isso para demonstrar como esse fenômeno é nacional. De 33 mil mortes de jovens por ano, nos últimos Atlas da Violência do IPEA, em que tem se repetido essa tragédia nacional, $71 \%$ das mortes são jovens negros. Então, o que o artigo denuncia? O Brasil está matando os seus jovens, primeiro não dando acesso à educação, segundo deixando-os presas fáceis das grandes facções e, terceiro, permitindo que sejam assassinados. E, a nível social, os jovens são as primeiras vítimas da violência policial, da perseguição aos jovens homossexuais, da violência contra as mulheres, seja violência doméstica, sexual (estupro) ou mesmo assédio. Os jovens têm sido, em todos as dimensões, as maiores vítimas da violência e de morte no Brasil. É uma tragédia extremamente grave, porque se queremos construir uma nação melhor hoje e no futuro, precisamos cessar o juvenicídio contra nossos adolescentes e jovens, fontes de vida e criatividade. O Brasil mata mais jovens que a guerra na Síria, no Iraque e outras guerras que estão transcorrendo.

6 - Considerando esse quadro tão assustador, que atitude esperar do governo Federal? Quais iniciativas diferenciam um bom governo de um mau governo? 
Grabowski: Do ponto de vista da ciência política, eu entendo que um bom governo é aquele que consegue, dentro da sua realidade, propor avanços no desenvolvimento econômico, social, educacional e cultural. Eu considero um governo de avanços quando ele tem um projeto de desenvolvimento do país, e que possa através da geração de trabalho e de renda incluir mais gente no processo produtivo da nação. Este projeto de desenvolvimento deve articular o desenvolvimento econômico com inclusão social, com melhor distribuição de renda, com melhores condições de vida, desde direito à habitação, direito ao transporte, direito à cultura e à própria educação. Este processo de desenvolvimento precisa ser acompanhado, estar integrado com a inclusão educacional e com o desenvolvimento intelectual dos cidadãos, mudando a mentalidade dos brasileiros. Não podemos ter apenas um desenvolvimento, com crescimento econômico, inclusão social, mas precisamos uma transformação cultural da população. Eu penso que foi o equívoco das políticas das últimas décadas, em que tivemos avanços em alguns campos mas retrocedemos culturalmente. A melhora econômica de 1996, desde o plano real, até 2015, não se transformou em um avanço cultural e intelectual. A prova disso é que em uma série de temas nós temos manifestações muito retrógradas, atacando museus, exposições, criticando a pluralidade e diversidade. A materialização desse retrocesso é a intolerância política, religiosa, de gênero e sexual. Então eu vejo que um governo desenvolvido, um bom governo, seria aquele capaz de fazer com que o país tenha um projeto de desenvolvimento nacional, integrando essas dimensões que vão do campo econômico ao cultural, do educacional ao tecnológico, com qualidade de vida. $\mathrm{O}$ grande problema do Brasil é essa falta de direção, de um horizonte, para onde possamos caminhar e nos desenvolver enquanto nação justa e soberana. Cada governo tem um programa e este deveria contribuir com o projeto nacional de desenvolvimento integrado e sustentável.

\section{7 - A autonomia da escola e da universidade de fato encontra-se ameaçada? Afinal, qual é a função da educação e qual o papel do professor?}

Grabowski: Sim, mais do que nunca. Eu entendo que o papel da escola e do educador, seja professor, seja pai, é desenvolver a autonomia do estudante em todas as suas dimensões. A primeira autonomia a ser desenvolvida é a intelectual, e eu pressuponho que todo pai, toda mãe, todo educador queira que seu filho, a criança, o adolescente, o estudante aprenda a pensar com a sua própria mente. Autonomia é o pensar próprio, desenvolvimento intelectual próprio, ou seja, o que ele aprende o auxilia a desenvolver a sua visão do mundo, a sua concepção do mundo, as suas ideias, os seus saberes, caso contrário ele sempre estará sujeito a depender de alguém. Essa é a importância do desenvolvimento da autonomia intelectual. A segunda dimensão é a autonomia ética, o estudante saber conduzir a sua vida em sociedade, em coletividade, por isso a importância dele desenvolver valores e princípios - que na ética nós chamamos de qualidades de virtudes -, que possibilitam viver com os outros em sociedades diversas e plurais. E, a terceira dimensão, é a autonomia política, ou seja, que ele possa ter os seus posicionamentos em relação ao mundo, à sociedade, em relação à própria cidadania, sem serem tutelados por nenhuma força política de qualquer ordem ou natureza. Quero 
reafirmar que a função da educação, dos educadores é o desenvolvimento desse estudante com autonomia intelectual, ética e política, seja da educação infantil ou da pós-graduação, para que ele possa ser um sujeito que construa a sua direção na vida, tanto na dimensão vida pessoal, na vida intelectual ou na vida profissional. Desenvolver os seus saberes e que estes possam interagir e conviver com outros saberes, sem atitudes de arrogância ou superioridade sobre os pares.

\section{8 - Falando em forças políticas, a gente vê de uns tempos pra cá cada vez mais professores e alunos sendo criminalizados. Por que a sociedade é tão complacente com as arbitrariedades de governos que criminalizam professores e alunos?}

Grabowski: Isso tem a ver com o que eu falava anteriormente, da nossa mentalidade enquanto cidadãos brasileiros. Um dos sociólogos que realizou uma pesquisa recentemente, que é o Alberto Carlos Almeida, no livro A cabeça do brasileiro, ele demonstra como o brasileiro pensa, e ele pensa exatamente como está agindo agora com os professores e com os alunos, ou seja, a mentalidade do brasileiro é extremamente familiar, configurando uma mentalidade hierárquica, muito preconceituosa, especialmente em relação à sexualidade e à étnica. Com o momento político que nós vivemos, estes preconceitos e intolerância se intensificaram. Essa mentalidade conservadora estava de alguma forma abafada, inibida e, com a polarização política atual, muitos se autorizam a expressar de uma forma pública e, inclusive, agressiva. Nesse contexto, essa atitude de acusação e de perseguição aos professores, está, por um lado, sendo incentivada pelas autoridades do governo federal, sugerindo filmagens ilegais e antipedagógicas. A posição dos dois últimos ministros da Educação, sugerindo gravações, em nada contribui com o ambiente escolar e visa deslegitimar ainda mais os educadores, tanto profissionalmente quanto como referências intelectuais. É um momento extremamente tenso, porém, eu penso que, com o passar do tempo, nós deveremos superar essa fase. Essa crise e essa intolerância deverá contribuir para que consigamos avançar na compreensão dos papéis de cada um no ambiente educacional e mesmo na sociedade. Agora, se vencer a tese da desconstituição, da deslegitimação do trabalho profissional científico da docência, aí sim, nós teremos um futuro bem mais difícil do que o presente. É comum do pensamento de extrema-direita liberal, ou do pensamento com características fascistas, desconstituir instituições sociais importantes. Eu vejo que a primeira instituição que foi desconstituída fortemente no Brasil foi a esfera da política, imprescindível para toda sociedade republicana e democrática. Ocorreu uma desconstituição dos políticos e das práticas políticas, do Congresso Nacional (Senado e a Câmara). Agora, estamos desconstituindo o judiciário como representação constitucional fundamental. Estamos atacando a institucionalidade da escola e, por conseguinte, da educação (e o PL do ensino domiciliar contribui nesta perspectiva). Atacamos universidades, escolas e professores. Isso está na mesma lógica de quando se acusa os políticos afirmando que todos são ruins e corruptos. Da mesma forma estamos dizendo que todos os professores são doutrinadores e isso não é verdade, e é muito grave na relação educador e estudante. Mas no senso comum, e com uma mentalidade tão frágil, do ponto de vista cultural da sociedade brasileira, isso acaba tendo aderência, e se 
constitui num perigo para o futuro do nosso país, da nossa democracia e da nossa educação. Estes ataques estão sendo direcionados para algumas áreas da esfera pública, como a política e a educação. Na educação, qualquer um pode opinar, atuar e gerir (vide notório saber), enquanto nas demais áreas e profissões há um respeito e reserva de mercado blindados. O perigo é desmoralizarmos a escola e a docência como já fizemos com a política, com os políticos e com as instituições do legislativo, comprometendo não somente o trabalho educativo, mas também, a democracia.

9 - Os 25 artigos do seu livro, escritos mensalmente, de janeiro de 2017 a janeiro de 2019, analisam projetos que propõem o desmonte da educação brasileira. Que análise o senhor faz do conjunto dessas medidas?

Grabowski: Iniciamos a entrevista lhe mencionando que a educação no Brasil vem sofrendo uma total reestruturação desde 2014, não só na redução dos investimentos, mas em toda a sua estruturação regulatória. Primeiro, o Brasil interrompe a tendência de crescimento de investimento em educação, reduzindo drasticamente os recursos. $\mathrm{O}$ governo Temer altera, neste mesmo período, todo o arcabouço regulatório legal, da educação básica à educação superior. Na educação básica, aprovaram a BNCC, a Reforma do Ensino Médio, mudaram a legislação da EaD no Brasil, bem como a legislação da educação do Ensino Superior. Aprovou-se, também, uma nova proposta de currículo (por competências e habilidades), aproximando-se das demandas do mercado. E todo esse conjunto de ataques às universidades e aos professores precisa ser analisado neste contexto geral de reformulações educacionais na perspectiva de submeter a educação à economia de mercado. É uma obra complexa, articulada, orquestrada em várias frentes. Nada aí está desconexo. A própria nomeação de gestores em Secretarias de Estado da Educação e no próprio Ministério da Educação, advindos de outras áreas que não a da educação são administradores vinculados à economia, demonstrando a necessária vinculação da formação e da educação aos interesses de produção econômica. Quando o ministro da educação e o presidente dizem "não vamos mais investir em ciências humanas", em desenvolvimento das pessoas, é sinal de que nós vamos tornar a educação cada vez mais um instrumento dos interesses da esfera econômica. E o livro a "Desconstrução do futuro" retrata os dois anos - de 2017 até 2019 -, em que todo este movimento se materializa, desconstruindo todas as políticas públicas na educação, comprometendo o futuro da juventude brasileira.

* Cristiano Goldschmidt é Jornalista, Escritor e Crítico Teatral. Pedagogo, possui Especialização em Pedagogia da Arte (Ufrgs, 2013), Especialização em Docência no Ensino Superior (Centro Universitário Leonardo da Vinci, 2018) e Mestrado em Artes Cênicas (Ufrgs, 2018). Atualmente é Conselheiro Estadual de Cultura do Governo do Estado do Rio Grande do Sul. 